\title{
Taste in Motion: The Effect of Projection Mapping of a Boiling Effect on Food Expectation, Food Perception, and Purchasing Behavior
}

\author{
Yuji Suzuki ${ }^{1}$, Takuji Narumi ${ }^{1,2 *}$, Tomohiro Tanikawa ${ }^{1}$ and Michitaka Hirose ${ }^{3}$ \\ ${ }^{1}$ Graduate School of Information Science and Technology, The University of Tokyo, Tokyo, Japan, ${ }^{2} J S T$ PRESTO, Tokyo, Japan, \\ ${ }^{3}$ Recearch Center for Advanced Science and Technology, The University of Tokyo, Tokyo, Japan
}

OPEN ACCESS

Edited by: Yoram Chisik,

University of Madeira, Portugal

Reviewed by:

Monchu Chen,

Appen, United States

Nimesha Ranasinghe,

University of Maine, United States

Meetha James,

University of Maine, United States, in collaboration with reviewer NR

${ }^{*}$ Correspondence: Takuji Narumi

narumi@cyber.t.u-tokyo.ac.jp

Specialty section: This article was submitted to

Human-Media Interaction,

a section of the journal

Frontiers in Computer Science

Received: 01 February 2021 Accepted: 19 April 2021

Published: 05 May 2021

Citation:

Suzuki Y, Narumi T, Tanikawa $T$ and Hirose $M$ (2021) Taste in Motion: The

Effect of Projection Mapping of a

Boiling Effect on Food Expectation,

Food Perception, and

Purchasing Behavior.

Front. Comput. Sci. 3:662824.

doi: 10.3389/fcomp.2021.662824
The appearance of food affects its taste. Many studies have examined how to improve the taste of foods by manipulating their appearance. Most of those studies have focused on static appearances, such as color and texture; however, the impact of the dynamic appearance has not been explored. In this study, the perceptions (sweetness, sourness, saltiness, spiciness, temperature, deliciousness) and value judgments (the price of food, appetite) perceived from food before and after tasting with a projection-based dynamic boiling texture were investigated. The results revealed that the dynamic texture influences expectations for saltiness, spiciness, temperature, deliciousness, price, and appetite before eating the meal and perceived saltiness, spiciness, and appetite when eating. In addition, its influence on the consumers' behavior was also investigated through an empirical user study in a restaurant. The results indicated that the consumers had a greater tendency to order the meal when they saw it with the projection-based boiling effect. From these, this study demonstrates the effect of projection mapping of a boiling effect on food expectation, perception and consumer behavior.

Keywords: human-food interaction, food, dynamic texture, food perception, food evaluation, projection mapping

\section{INTRODUCTION}

The appearance of food, such as color (Zampini et al., 2007) and shape (Velasco et al., 2015), is a factor that has a great influence on the culinary experience. In addition, a meal's appearance changes the consumers' behavior (Alfnes et al., 2006; Aslam 2006; Clement 2007; Kuvykaite et al., 2009) and the evaluation of the quality (Hagtvedt and Patrick 2008; Van Rompay et al., 2012; Labrecque and Milne 2012). As such, a significant amount of research has been focused on the appearance of food for marketing purposes. Although there has been research conducted on the effect of appearance of food on perception of food and the culinary experience, inquiries into engineering techniques to apply this knowledge is a new area of research - Human-Food Interaction.

Previous Human-Food Interaction research aimed at changing the eating experience by manipulating the appearance of food. Most of those studies has focused on the effect of static appearances such as color, shape, texture, and size on food perception and the culinary experience (Narumi et al., 2011; Narumi et al., 2012; Nishizawa et al., 2016; Fujimoto, 2018; Nakano et al., 2019). Meanwhile, the dynamic appearance of food also plays an important role when dining (Gvili et al., 2015). Occasionally, food is served in motion, changing its appearance from moment to moment. The motion of the food is defined here as the movement the food has when it is served. The motion of 
the food can be a critical clue to understanding its freshness (Kruger et al., 2004; Pham and Avnet, 2009; Chang and Pham, 2013). Living animals move; Healthy animals move more than diseased animals; A freshly cooked pot emits steam remove and bubbles; A freshly opened bottle of champagne is filled with bubbles. Dynamic textures of a meal including the boiling of hot liquids, the rising of steam, melting ice, and shimmering motions contribute to the estimation of food quality. These motions also bring a sizzling feeling to the food. For instance, if a hot pot seems to be boiling, it may stimulate hunger and increase one's expectations for the dish.

However, these dynamic textures can disappear when you stop heating the pot. Currently, the development of digital technologies enables us to add these dynamic textures to lukewarm dishes to make them appear very hot. The purpose of this study is to demonstrate the unknown effects of adding dynamic textures to food with the aid of digital technologies. In particular, this study focuses on the effect of dynamic boiling textures. This approach also contributes to control experimental conditions other than the dynamic boiling texture. Therefore, it enables us to investigate the effect of dynamic boiling textures without being affected by other stimuli such as actual temperature.

To investigate the effect of adding dynamic textures to meals, this study developed a system to project the motions onto dishes and the research was focused on the boiling motion. Our experiment investigates whether projecting a boiling-motion texture enhances the perceptions (sweetness, sourness, saltiness, spiciness, temperature, deliciousness) and value judgments (the price of food, appetite) perceived from food. In particular, by comparing the perceptions and value judgments expected before eating the food with those felt after eating, we examine how changes in perception and value judgments occur. Moreover, an empirical user study was performed in a restaurant where a food item was displayed at the entrance and had a boiling motion. This was done to determine if the boiling motion influences the purchase behavior (the ordering rate of the dish).

This research makes the following contributions. First, it contributes to the field of investigating the relationship between material perception via vision and perception of food/ eating behavior. Although research on the relationship between the static texture and food has been widely carried out (Morrot et al., 2001; Zampini et al., 2007; Wada et al., 2010; Velasco et al., 2015; Chung and Fong 2018; Paakki et al., 2019), the relationship between dynamic textures and the dining experience has been rarely investigated. In addition, this technique is also useful for multisensory food marketing. For example, there are many restaurants where food model displays are placed at the front of their shops. These food model displays present information to customers about the cuisine, and they are used to attract customers in Japan. By applying the proposed technique to food displays, it is hypothesized that this technique would attract more customers. It is also possible to draw attention from consumers by providing dishes with a dynamic texture as a new culinary experience.

\section{CONCEPTUAL BACKGROUND}

\section{Appearance of Food and Culinary Experience}

This study investigates the culinary experience when combined with dynamic textures. Before introducing the concept of the dining experience with new technologies, this section presents the relationship between the appearance of food and the dining experience. Because the appearance of food is related to the perceived taste as well as the preference and purchasing behavior, many studies have been performed to clarify this relationship. For example, the color of food is reported to influence the consumers' evaluation of the taste and flavor (Morrot et al., 2001; Zampini et al., 2007; Wada et al., 2010; Paakki et al., 2019). One study investigated the effect of the color of a drink and the predicted flavor. This study revealed that the participants who drank the improperly colored beverage significantly failed to discriminate the flavor even though they were told that the drink color is useless to discriminate its flavor (Zampini et al., 2007). In addition, the influence of color is not limited to public consumers. Even trained panelists have described white wine that was colored red with an odorless dye as red wine (Morrot et al., 2001). Previous studies have reported that luminance and saturation are also important for food. The distribution of luminance is one of the indicators that represents the freshness of cabbage (Wada et al., 2010). In addition, colorful and high-contrast salad portions are reported to be associated with freshness and visual attractiveness (Paakki et al., 2019).

The shape of food can also have an influence on the eating experience. Velasco et al. (2015) investigated the correspondence between the shape and taste. Velasco et al. reported a tendency to associate sweetness with rounded shapes and sourness with angular shapes. As for children, transforming fruits and vegetables into snack like shapes, such as popsicles or pancakes, increases their consumption and appetite for these food products (Chung and Fong, 2018).

Both the appearance of food and its presentation are important factors that can influence the diners' reaction. For example, if the food arrangement is more attractive, the diners will have a more favorable evaluation in terms of liking the dish and they will be willing to pay more (Zellner et al., 2010; Zellner et al., 2011; Zellner et al., 2014; Michel et al., 2014; Michel et al., 2015). Multisensory cues from cutlery also influences the eating experience. For instance, yoghurt is perceived denser and more expensive when it is tasted from a heavier spoon in comparison to a lighter spoon (Harrar and Spence, 2013).

The appearance of food not only affects the consumption of food, but it also changes the purchasing behavior of consumers. For example, Loebnitz and Grunert (2015) examined the effect of food shape abnormality for two kinds of vegetables and two kinds of fruits in terms of purchasing intentions. This shows that the purchasing intention is lower for food with an abnormal shape than for food with a normal shape. Another study investigated the affective impression of the packaging of chocolate bars and the 
snack itself to create a coherent design in terms of Kansei Engineering (Schütte, 2013).

In this study, we deal with dynamic textures in food appearance. When we think of texture in food, we tend to think of mouthfeel. In this paper, we use the term dynamic texture as a visual feature that conveys motion, rather than mouthfeel. Doretto et al. (2003) defined that dynamic textures are sequences of images of moving scenes that exhibit certain stationarity properties in time; these include sea-waves, smoke, foliage, whirlwind etc. These visual characteristics are especially evident in freshly prepared foods. That's why these visual features affect the judgment of food freshness. These effects are often used in advertising. Gvili et al. (2015) investigated whether the oftenused depiction of foods in motion both on packaging and in marketing campaigns helps improve consumer judgments of food products and showed that depictions of food with implied motion led to enhanced evaluations of both freshness and appeal. A number of studies have shown that the perception of food freshness can lead to strong sensory features and feelings of attractiveness from food (Steenkamp and van Trijp, 1996; Cardello and Schutz 2003). Therefore, we hypothesized that adding dynamic texture to food by projection mapping would improve the sensory perception of food (especially the smell, heat, and intensity of flavor that are strongly felt in freshly cooked food), the palatability of food, and the value judgment of food.

\section{Manipulation of the Appearance of Food with Digital Technologies for Improving Taste}

The research described in the previous section manipulates the appearance of the food by modifying the food itself. However, this method may damage the taste and texture/mouthfeel of food. It is not practical since it requires great care. In the meantime, methods that use digital technology are being used to manipulate the space around food or appearance of food. This can be achieved by applying a head-mounted display (HMD) or a projection mapping technique. By taking advantage of these technologies, ample research has been conducted to investigate the effects of changes in the appearance and environment of food without modifying the food itself. For example, Narumi et al. (2011) devised a system so that a plain cookie had a variety of flavors such as chocolate or strawberry. This was achieved by displaying corresponding images that were superimposed onto the cookie. This was achieved using an HMD and simultaneously presenting the fragrance materials. In addition, Nakano et al. (2019) constructed a system that replaces the appearance of food displayed using an HMD. This was performed by superimposing different food images of food in real time in response to the changes in the shape of the food item.

In these studies, the appearance of food is manipulated by superimposing the images on the food displayed using an HMD; however, it is not realistic to have dinner with an HMD. Projection mapping is an attractive technology as it can enhance the meal experience without a user wearing any equipment. For example, Nishizawa et al. (2016) constructed a projector-camera system that is capable of changing the appearance of food and tableware in real time, which demonstrates that enhancing the saturation of castella causes the enhanced perceived sweetness. In addition, they also revealed that enhancing the hue of potato chips leads to changes in the flavor. Fujimoto (2018) also makes it possible to improve the taste under normal lighting by projecting images on food products. This produces modifications through chroma, highlighting, and partial colors.

Some of food appearances can be controlled by making various 'actual' food. For example, the color of food was controlled by actually dying food in previous research (Morrot et al., 2001; Zampini et al., 2007; Paakki et al., 2019). Meanwhile, digital technology including augmented reality and projection mapping allows manipulation of appearance without actual food processing. This helps to more rigorously investigate the effects of appearance that have been tested using the traditional approach using food processing. Moreover, it is also expected to help to verify effects that have been impossible to verify due to the difficulty of controlling factors with food processing. For example, Narumi et al. (2012) conducted a study on the manipulation of food intake by producing an illusion of portion size. This was achieved by rescaling the size of the food relative to the size of a hand or tableware displayed via an HMD with augmented reality. In this case, the effect of "perceived" food volume on satiety was purely investigated by changing the apparent size of food without changing its "actual" volume. A projection mapping technique also controls only the difference in the apparent amount when eating the same thing. Sakurai et al. (2013) also reported a study on controlling the feeling of fullness by dynamically changing the size of the plate. Without digital technology, it would be difficult to validate that dynamically changing the size of the projected eating utensils in response to the reduction in food consumption would lead to effective changes in food intake.

The motion of the food is a particularly difficult factor to control and has been difficult to verify with the traditional approach. However, these digital technologies make it possible to control the motion of the food. Although studies on investigating the relationship between the motion of the food and food perception are conducted, the concern has been limited to its acceptability (Spence, 2018). For example, some studies have focused on the crossmodal correspondences between taste and movement in animation (Huisman et al., 2016). Huisman et al. investigated associations between basic tastes and visualizations that differed in color, shape and animation speed, and revealed that associations between sweetness and red rounded shapes, and sourness and green angular shapes with a fast animation speed. They also have a lab study where the visualizations were projected around a cup of yogurt that participants tasted confirmed these associations, and specific combinations of visualizations and animation types were found to influence taste perceptions. This study shows that it is possible to influence taste by providing visual stimuli that are not directly related to the food. In contrast, our research aims to investigate the changes in sensory perception, preferences of foods, and purchasing behavior that are accentuated by 


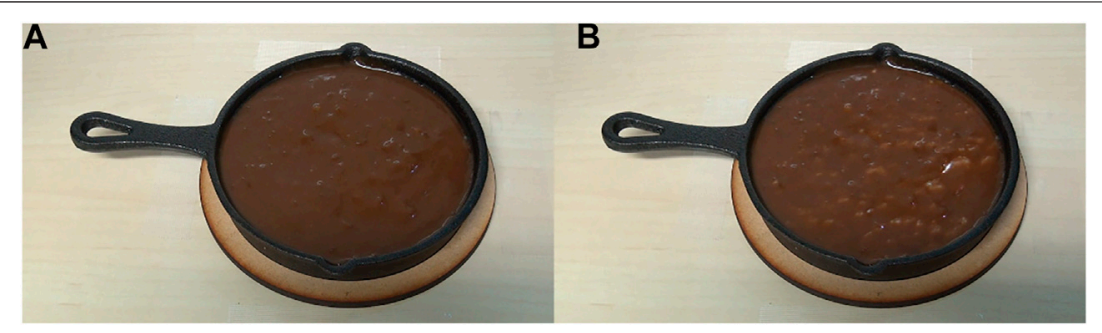

FIGURE 1 | (A) Curry with the single color projected and (B) with the boiling effect projected.

heating by projecting the movements that foods are expected to have when they are heated.

\section{EXPERIMENT}

There are two methods to add dynamic textures to food; superimposing textures using an HMD and projecting textures onto the target food using a projector. To make the dining experience more realistic and to reduce the user's effort, this study adopted projection mapping. Among the dynamic textures found in dishes, the boiling motion was selected for this study. This is because boiling is applicable to various foods such as gratin, curry, and hot pot meals. Among these foods, this study selected Japanese curry as the projection target because it is a very popular food that most Japanese like.

\section{Method}

\section{Conditions, Apparatus, and Food Stimuli}

Two types of images were projected in this study (projection conditions): one expressed a static single-color image (Figure 1A) and the other showed a dynamic boiling motion (Figure 1B). The movies of them can be found online (curry with a static singlecolor image projection ${ }^{1}$ and curry with a dynamic boiling motion projection $^{2}$ ). Previous studies have reported that the luminance (Wada et al., 2010) and saturation (Nishizawa et al., 2016) of food affect the food perception. Therefore, in this experiment, to investigate only the effect of dynamic texture by eliminating as much as possible the effect of changes in luminance and saturation due to projection on the food perception, we decided to use a static single-color image projection as the control condition, in which an image with a color equal to the average luminance of the projected dynamic boiling motion is always projected. This is the reason why we used the static singlecolor image projection as the control condition in this experiment, instead of the no-projection condition. However, as a result, there is no significant change in appearance between no-projection and the static single-color image projection.

The dynamic texture projected were created by reference to the deformation lamps (Kawabe et al., 2016), which is a technique that adds a variety of illusory motion by projecting only dynamic

${ }^{1}$ https://youtu.be/WFjxJJvDl_E

${ }^{2}$ https://youtu.be/TtsrUpw3tBw

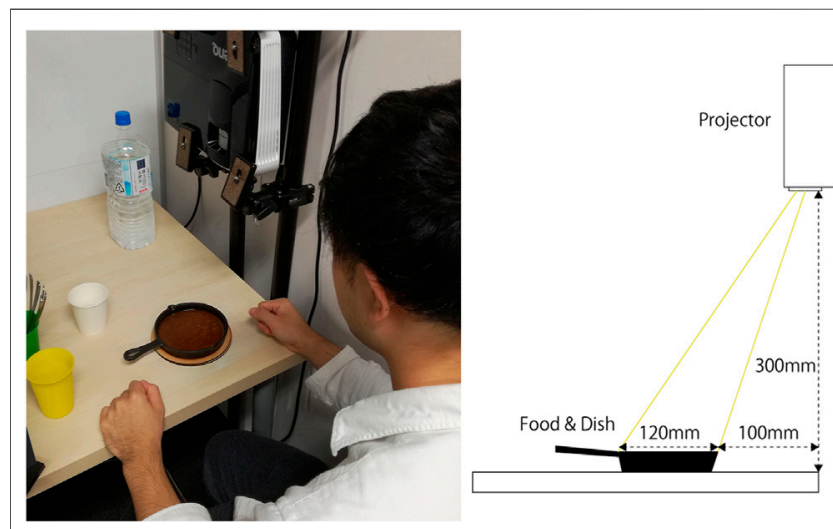

FIGURE 2 | Experimental setup.

luminance information onto $2 \mathrm{D} / 3 \mathrm{D}$ objects. The detailed procedure to create the motion images were as follows. First, we recorded a boiling motion of curry using a video camera. An image before heating and images during heating in the recorded video were converted to gray scales and the difference was taken. The images created through this process had their dynamic luminance information extracted from the boiling motion. These were projected onto the actual food to give the observer that boiling was occurring. For realizing natural appearance of the curry with the boiling motion, multiple image processing methods were applied as follows: A gamma correction $(\gamma=$ 1.3) and a linear color correction (minimum brightness 0 , maximum brightness 192) were conducted and a color $(\mathrm{R}=$ $82, \mathrm{G}=65, \mathrm{~B}=41$ ) was applied to the gray scale images. Mask processing was also performed so the effects were only applied to the curry area. The single-color image used a color obtained by averaging all the luminance values in the animation of the boiling motion. By doing so, we aligned the temporal average of the apparent brightness of the food across image conditions.

Two temperature levels for the curry were prepared and presented to each participant (temperature conditions). First, $100 \mathrm{ml}$ of curry was poured into a container and heated at $65^{\circ} \mathrm{C}$ and $80^{\circ} \mathrm{C}$ for approximately $1 \mathrm{~h}$ in a pot using a low temperature cooker. Curry was tasted by the participants 3 min after being taken out from the pot. At that time, the temperature of the curry was approximately $50^{\circ} \mathrm{C}$ and $60^{\circ} \mathrm{C}$, respectively. 
As there were two factors (projection and temperature) and two levels (projection: boiling motion and single-color image; temperature: $50^{\circ} \mathrm{C}$ and $60^{\circ} \mathrm{C}$ ), a total of four experimental conditions were prepared. The experiment was conducted within-participants design. The participants experienced all the conditions $\left(50^{\circ} \mathrm{C}\right.$-single-color image, $50^{\circ} \mathrm{C}$-boiling motion, $60^{\circ} \mathrm{C}$ single-color image, $60^{\circ} \mathrm{C}$-boiling motion) once in a counterbalanced order, then the participants sampled the curry four times.

An ultra-short throw projector (TH682ST, BenQ Corporation, Taiwan) was used to project the effects. The brightness of the projector was $3000 \mathrm{~lm}$. Figure 2 shows the experimental setup. The projector was set up at a height of $300 \mathrm{~mm}$ from the table surface. The curry was served on a skillet of $120 \mathrm{~mm}$ in diameter. The position of the skillet was predetermined, and the skillet was placed so that the image was projected on it. Participants were not allowed to move the skillet, but were only allowed to sit and observe, and to taste the curry with a spoon. The room where the experiment was conducted was lit with normal room lighting.

Pre-packaged curry (MIYAGI SEIFUN Co., Ltd., Japan) was chosen as a food stimulus because of its uniformity and incompatibility with the boiling effect. This curry is made by stewing fond de veau, tomatoes, onions, carrots, apples, etc. with curry powder. It has the common characteristics of Japanese curry, dark brown in color, with a thick and rich flavor. Owing to the consistent quality of commercially available curry, the effects of individual taste differences of a meal can be ignored in this experiment. Curry was served to the participants in a skillet to assure their comfort with the superimposed boiling effect.

\section{Participants}

Twenty-four participants (12 females and 12 men, mean age 26.4 years, standard deviation $=6.86$ years, range $=20-43$ years) were recruited for this study through the Internet. None of the participants reported any allergies to the food ingredients for the curry that was used in the study and all the participants had eaten curry before. In addition, the participants were paid 1,000 JPY (approximately 9.2 USD) per person.

\section{Procedures}

The participants were invited to a waiting place, they received an explanation of the study, and they signed a consent form. At that time, they were told that the purpose of the experiment was to evaluate the taste of the curry. The participants were instructed to have a sip of water to refresh their mouth and had to wait until the experiment was prepared.

Each trial in this experiment was conducted as follows. First, the participant moved from the waiting place to the experiment place. There was curry poured into a skillet on the table. The appropriate effect for the condition was projected on the curry. The participants were not informed that some images were being projected onto the curry. Next, the participant was asked to rate the taste (e.g., sweetness, sourness, and saltiness), spice level, smell, deliciousness, hotness, price, and appetite just from its appearance while looking carefully at the curry. Each item of the questionnaire featured a 101-grade Visual Analog Scale that ranged from 0 (not at all) to 100 (very much). The questionnaire was conducted for $2 \mathrm{~min}$ to control the temperature of curry each participant ate in each trial. After filling in the questionnaire, the participant tasted a scoop of curry and responded to the same questionnaire. Before the participant started to answer the questionnaire, the skillet was taken away and the projected effect was stopped. At the end, the participant drank a sip of water, moved to the waiting place, and rested for 2 min.

Each participant repeated this trial four times. Finally, the participants were told that the purpose of the experiment was to assess how their taste changes due to the projected effects. The experiment lasted for about $40 \mathrm{~min}$ for each participant.

\section{Data Analysis}

There were two factors in this experiment: the image and temperature of the food. These two factors each had two levels (projection: boiling motion and single-color image; temperature: $50^{\circ} \mathrm{C}$ and $60^{\circ} \mathrm{C}$ ); thus, a $2 \times 2$ repeated measures ANOVA was performed for each item of the questionnaire, which was taken before and after tasting. For each item on the questionnaire, Bartlett's test was carried out to confirm the homogeneity of the variance. In addition, the Shapiro-Wilk test was also conducted for each factor and level to check the normality. If homogeneity of variance was not recognized or there was an abnormally distributing item, aligned rank transform (ART) was applied before ANOVA was performed and the results were reported with boxplot charts. ART was the procedure to transform non-parametric data to the format ANOVA can be applied. If the normality assumption is not violated, we just applied an ANOVA and showed the results as bar charts. When the interaction effect was significant, simple effects and an interaction contrast was examined. Multiple comparisons were also performed using the Wilcoxon signed-rank test, which applied Holm's method. All analyses were performed using $\mathrm{R}$.

\section{Results}

In this experiment, most participants noticed that some images were projected onto the curry because the projector was located in a position where users could see it as shown in Figure 2. On the other hand, some participants did not notice the projection.

For the sweetness expectation before tasting (Supplementary Figure S1A), the homogeneity of the variance and normality were observed, and ANOVA was performed. No main effect of the image $\left(F(1,21)=0.037, p=0.849\right.$, partial $\left.\eta^{2}=0.002\right)$ and temperature $\left(F(1,21)=3.757, p=0.065\right.$, partial $\left.\eta^{2}=0.140\right)$ was observed. In addition, no interaction between the image and the temperature $\left(F(1,21)=0.124, p=0.728\right.$, partial $\eta^{2}=$ $0.005)$ was observed. For the perceived sweetness after tasting (Supplementary Figure S1B), the Shapiro-Wilk test showed non-normality and when ART applied ANOVA was conducted, no main effect of the image $(F(1,23)=0.205, p=$ $0.655)$ and the temperature $(F(1,23)=0.152, p=0.700)$ was observed. The interaction effect between the image and the temperature was also not observed $(F(1,23)=0.001, p=0.978)$.

For the sourness expectation before tasting (Supplementary Figure S2A), the homogeneity of the variance and normality were 

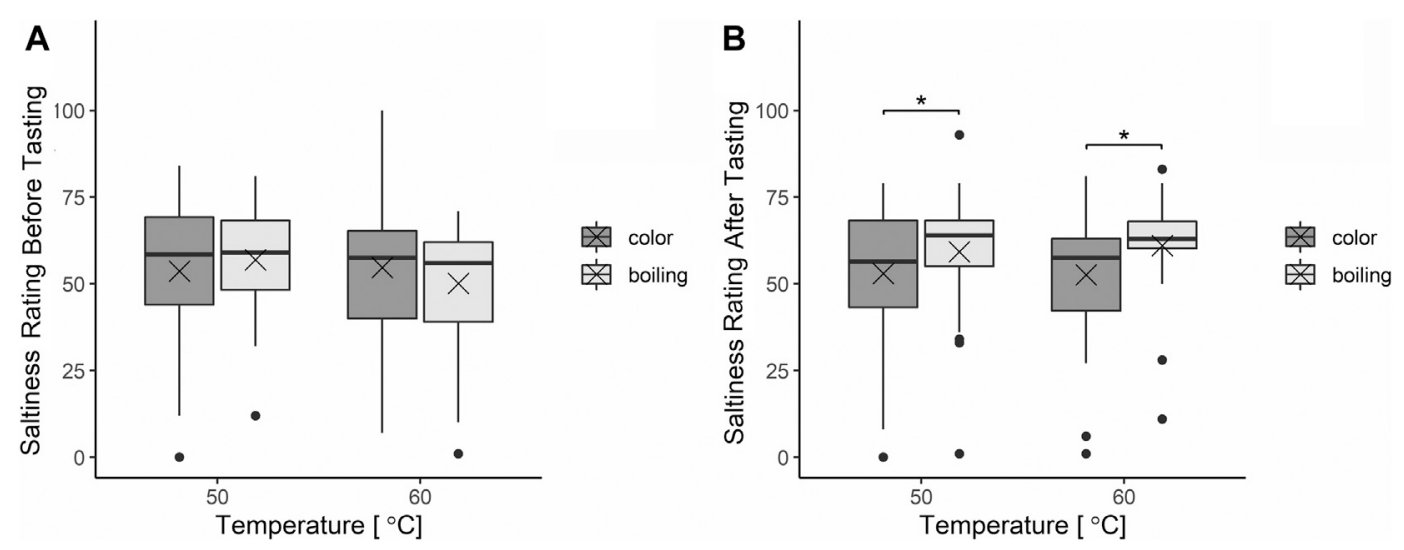

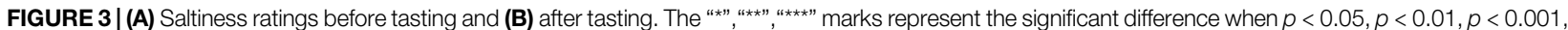
respectively. The error bars in the bar plots represent the standard error. For the box plots, the bold lines indicate the median, the boxes signify the range from the first quartile to the third quartile, the whiskers indicate the minimum and maximum values, the cross marks represent the mean average, and the points indicate the outliers.
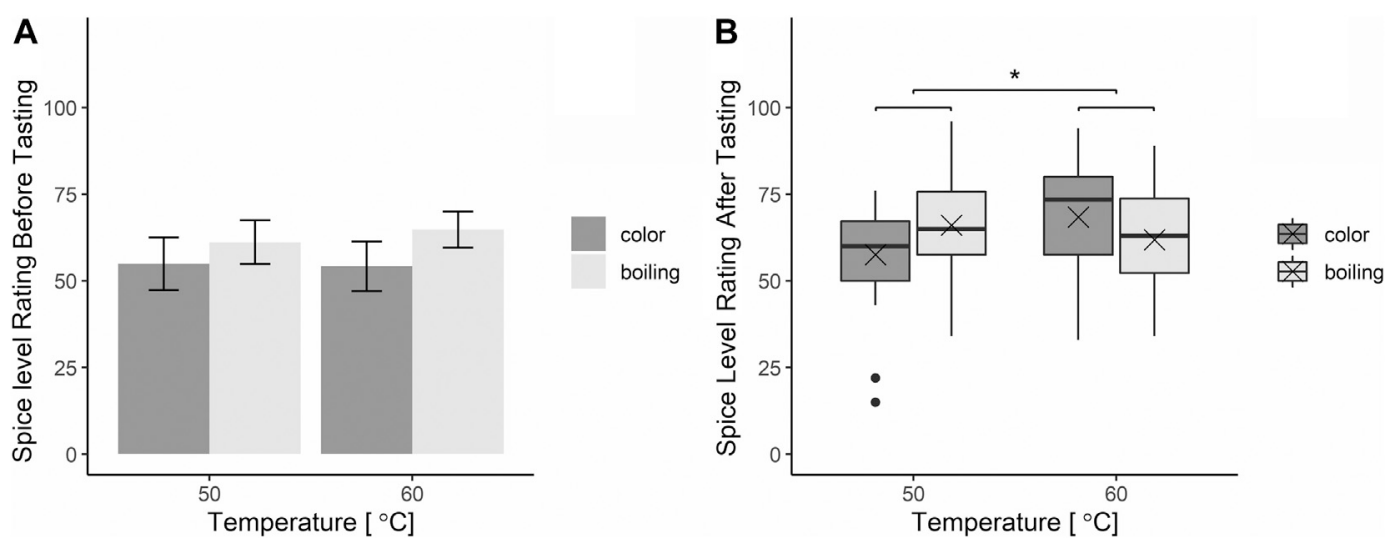

FIGURE 4 | (A) Spice level ratings before tasting and (B) after tasting.

observed, and ANOVA was performed. No main effect of the image $\left(F(1,21)=0.041, p=0.841\right.$, partial $\left.\eta^{2}=0.002\right)$ and the temperature $\left(F(1,21)=3.906, p=0.060\right.$, partial $\left.\eta^{2}=0.145\right)$ was observed. In addition, no interaction between the image and the temperature $\left(F(1,21)=3.149, p=0.0892\right.$, partial $\left.\eta^{2}=0.120\right)$ was observed. For the perceived sourness after tasting (Supplementary Figure S2B), the Shapiro-Wilk test showed non-normality. When ART applied ANOVA was conducted, neither main effect of the image $(F(1,23)=0.171, p=0.683)$ nor the temperature $(F(1,23)=0.163, p=0.690)$ was observed. The interaction effect between the image and the temperature was also not observed $(F(1,23)=1.797, p=0.193)$.

For the saltiness ratings before and after tasting, the ShapiroWilk test showed non-normality. ART applied ANOVA was conducted for the before tasting ratings (Figure 3A); no main effect of the image and the temperature and the interaction effect was observed $(F(1,23)=0.018, p=0.895, F(1,23)=2.321, p=$ $0.141, F(1,23)=0.914, p=0.349$, respectively). When ART applied
ANOVA was conducted for the after tasting ratings (Figure 3B), no main effect of the temperature $(F(1,23)=0.000, p=1.000)$ and no interaction effect between the image and the temperature was observed $(F(1,23)=0.005, p=0.945)$. However, the boiling effect significantly increased the perceived saltiness in comparison to the single color $(F(1,23)=7.871, p<0.05)$.

For the spice level expectation before tasting (Figure 4A), the homogeneity of the variance and normality were observed, and ANOVA was performed. There was no effect of the image $\left(F(1,21)=3.386, p=0.079\right.$, partial $\left.\eta^{2}=0.128\right)$ and the temperature $\left(F(1,21)=0.216, p=0.647\right.$, partial $\left.\eta^{2}=0.009\right)$. In addition, there was no interaction effect between the image and the temperature $\left(F(1,21)=0.590, p=0.450\right.$, partial $\left.\eta^{2}=0.025\right)$. In terms of the perceived spice level after tasting (Figure 4B), the Shapiro-Wilk test showed non-normality and ART applied ANOVA was conducted. Although no effect of the image $(F(1,23)=0.008, p=0.929)$ and the temperature $(F(1,23)=$ $1.642, p=0.213)$, the significant interaction effect was observed 

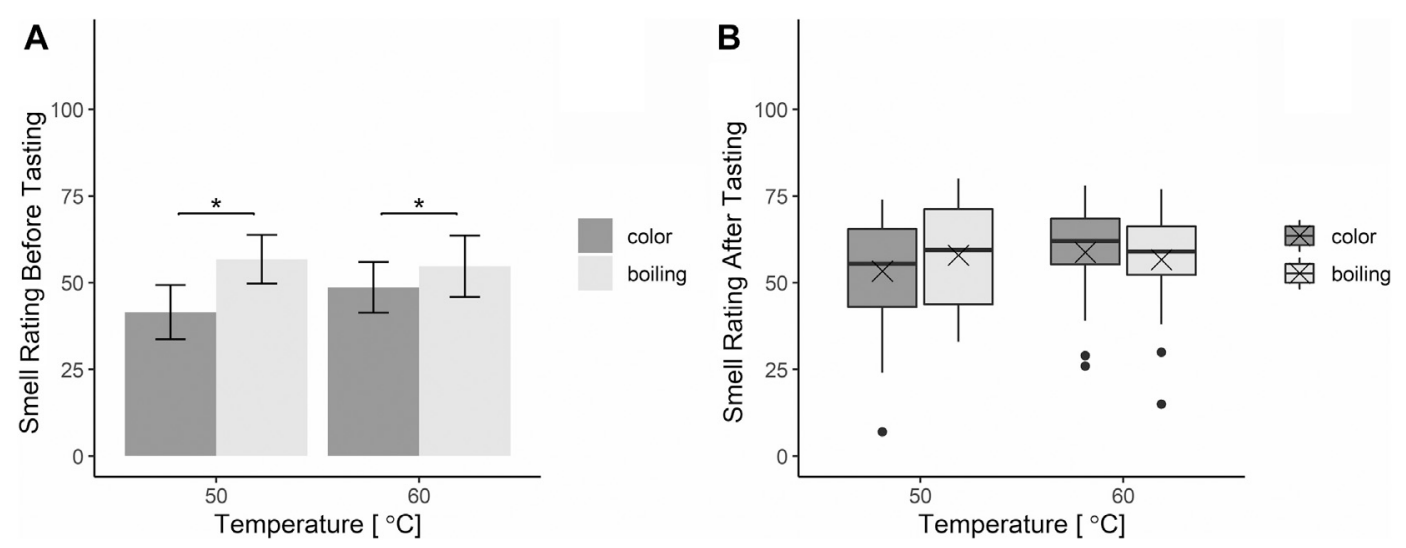

FIGURE 5 | (A) Smell ratings before tasting and (B) after tasting.
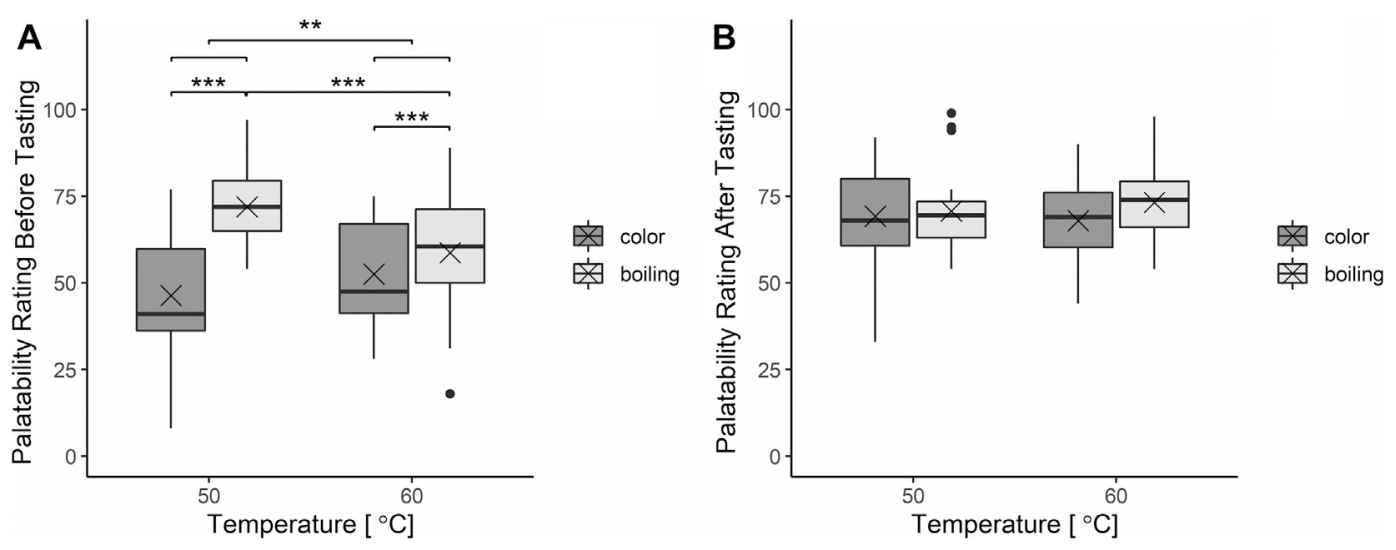

FIGURE 6 | (A) Palatability ratings before tasting and (B) after tasting.

$(F(1,23)=7.532, p<0.05)$. The test of the interaction contrast showed that there was the significant difference in the difference between projected images in $50^{\circ} \mathrm{C}$ condition and $60^{\circ} \mathrm{C}$ condition $(t(23)=2.745, p<0.05)$. To be precise, in the $50^{\circ} \mathrm{C}$ condition, the curry with the boiling image was evaluated spicier. On the other hand, in the $60^{\circ} \mathrm{C}$ condition, the curry with the single color projected was evaluated spicier.

For the perceived smell before tasting (Figure 5A), the homogeneity of the variance and normality were observed, and ANOVA was performed. There was no main effect due to the temperature $\left(F(1,21)=0.572, p=0.457\right.$, partial $\left.\eta^{2}=0.024\right)$ and there was no interaction effect between the image and the temperature $\left(F(1,21)=1.285, p=0.269\right.$, partial $\left.\eta^{2}=0.053\right)$. However, the boiling effect significantly increased the perceived smell in comparison to the single color $(F(1,21)=5.657, p<0.05$, partial $\left.\eta^{2}=0.197\right)$. For the perceived smell after tasting (Figure 5B), the Shapiro-Wilk test showed non-normality and when ART applied ANOVA was conducted, there was no significant main effect of the image $(F(1,23)=0.112, p=$ $0.740)$ and the temperature $(F(1,23)=0.575, p=0.456)$, and no interaction effect between the image and the temperature $(F(1,23)=0.950, p=0.340)$.

In terms of rating if the food looked delicious before tasting (Figure 6A), the Shapiro-Wilk test showed non-normality and when ART applied ANOVA was conducted, a main effect of the temperature was not significant $(F(1,23)=1.043, p=0.318)$. On the other hand, a main effect of the image was significant $(F(1,23)=19.439, p<.001)$ and the interaction effect between the image and the temperature was also significant $(F(1,23)=10.733$, $p<0.01$ ). The test of a simple effect of projection showed that the boiling effect significantly increased the estimation of palatability $(t(23)=4.409, p<0.001)$. Multiple comparisons revealed that curry with the boiling effect looked more delicious than curry with the single-color effect at $50^{\circ} \mathrm{C}(p<0.001)$, and that curry heated at $50^{\circ} \mathrm{C}$ got higher palatability estimation than curry heated at $60^{\circ} \mathrm{C}$ when the boiling effect was projected $(p<$ $0.01)$. Regarding the perceived palatability of the food after tasting (Figure 6B), the Shapiro-Wilk test showed nonnormality. When ART applied ANOVA was conducted, there was no significant main effect (the image: $F(1,23)=1.220, p=$ 

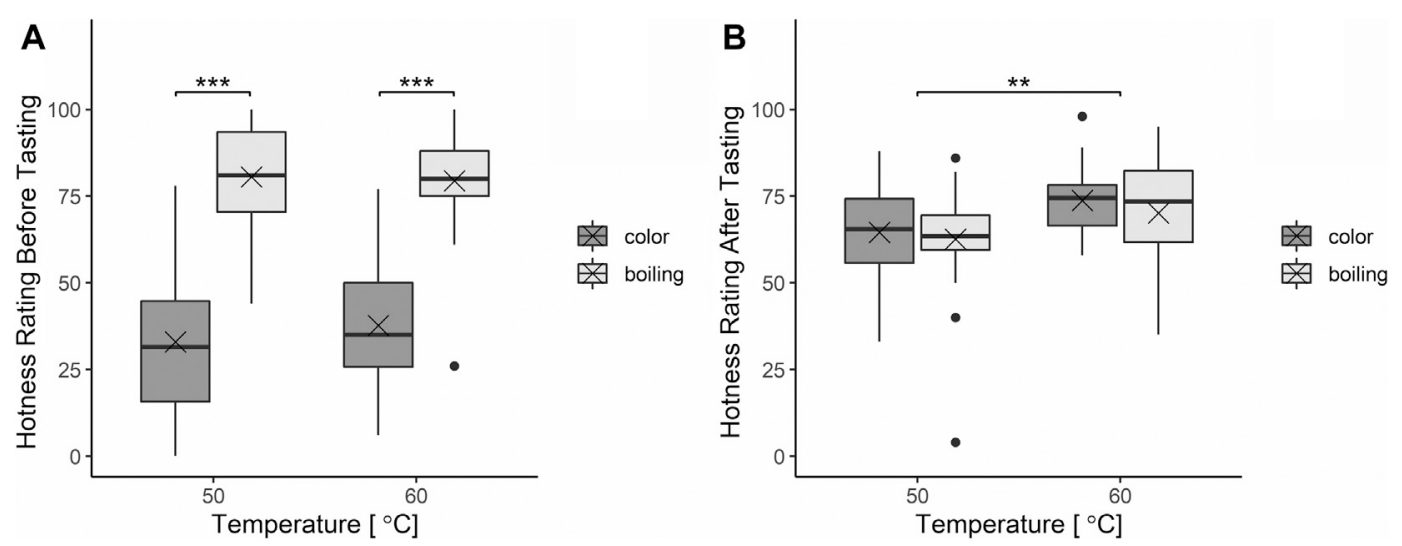

FIGURE 7 | (A) Ratings of the hotness of the curry before tasting and (B) after tasting.
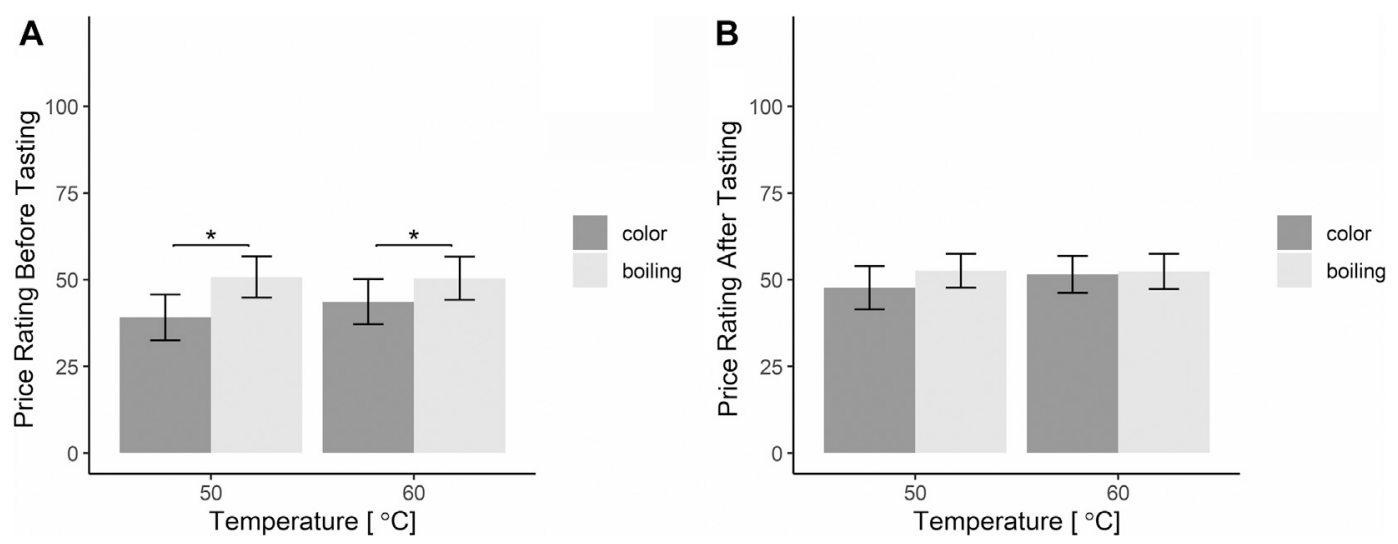

FIGURE 8 | (A) Price ratings before tasting and (B) after tasting.

0.281 , the temperature: $F(1,23)=0.269, p=0.609)$ and no interaction effect $(F(1,23)=1.188, p=0.287)$ was observed.

For the hotness expectation before tasting (Figure 7A), the Shapiro-Wilk test showed non-normality. When ART applied ANOVA was conducted, no main effect of temperature $(F(1,23)=$ $0.339, p=0.566)$ and no interaction effect $(F(1,23)=0.480, p=$ 0.495) was observed; however, the boiling effect was shown to increase hotness expectation compared to the single color effect $(F(1,23)=132.343, p<0.01)$. In terms of perceived hotness of the curry after tasting (Figure 7B), the Shapiro-Wilk test showed non-normality. When ART applied ANOVA was conducted, no main effect of the image $(F(1,23)=0.710, p=0.408)$ and no interaction effect $(F(1,23)=0.013, p=0.911)$ was observed. In contrast, participants rated the $60^{\circ} \mathrm{C}$ curry was hotter than the $50^{\circ} \mathrm{C}$ curry $(F(1,23)=9.000, p<0.001)$.

When estimating the price before tasting (Figure 8A), the homogeneity of the variance and normality were observed, and ANOVA was performed. There was no main effect of the temperature $\left(F(1,21)=0.323, p=0.575\right.$, partial $\left.\eta^{2}=0.014\right)$ and there was no interaction effect between the image and the temperature $\left(F(1,21)=1.263, p=0.273\right.$, partial $\left.\eta^{2}=0.052\right)$. For the image, the boiling effect significantly increased the estimation of the curry price in comparison to the single color $(F(1,21)=$ 5.233, $p<0.05$, partial $\left.\eta^{2}=0.185\right)$. For the estimated price after tasting (Figure $\mathbf{8 B}$ ), the homogeneity of the variance and normality were observed, and ANOVA was performed. There was no main effect for the image $(F(1,21)=1.211, p=0.283$, partial $\left.\eta^{2}=0.050\right)$ and the temperature $(F(1,21)=0.931, p=$ 0.345 , partial $\eta^{2}=0.039$ ). In addition, there was no interaction effect between the image and the temperature $(F(1,21)=0.717$, $p=0.406$, partial $\eta^{2}=0.030$ ).

For the perceived appetite before tasting (Figure 9A), the homogeneity of the variance and normality were observed, and ANOVA was performed. There was no main effect of the temperature $\left(F(1,21)=0.123, p=0.729\right.$, partial $\left.\eta^{2}=0.005\right)$. On the other hand, the boiling effect significantly fueled the participants' appetite in comparison to the single color $(F(1,21)=$ 15.754, $p<0.001$, partial $\left.\eta^{2}=0.407\right)$. There was an interaction effect between the image and the temperature $(F(1,21)=4.991$, $p<0.05$, partial $\left.\eta^{2}=0.178\right)$. Multiple comparisons revealed that 

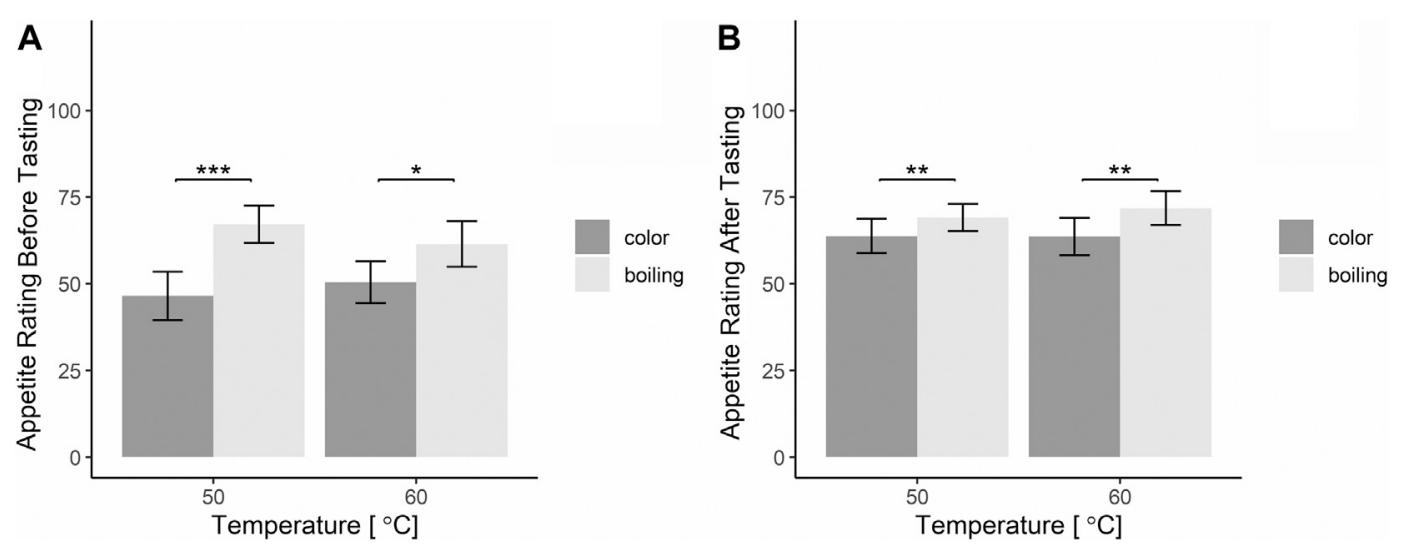

FIGURE 9 | (A) Appetite ratings before tasting and (B) after tasting.

the curry with the boiling effect stimulated the appetite more than the curry with the single color for both temperatures $(p<0.001$ for $50^{\circ} \mathrm{C}$, and $p<0.05$ for $60^{\circ} \mathrm{C}$ ). For the perceived appetite after tasting (Figure 9B), the homogeneity of the variance and normality were observed, and ANOVA was performed. There was no main effect of the temperature $(F(1,21)=0.280, p=0.602$, partial $\left.\eta^{2}=0.012\right)$ and there was no interaction effect between the image and the temperature $\left(F(1,21)=0.415, p=0.526\right.$, partial $\eta^{2}$ $=0.018)$; however, the main effect of the image was significant $\left(F(1,21)=8.332, p<0.01\right.$, partial $\left.\eta^{2}=0.266\right)$.

\section{Discussion}

The purpose of this study was to investigate the influence of the projected dynamic boiling texture when evaluating the dining experience. Since most of the participants were aware of the projection, it is considered that the results of this experiment basically showed the change in perception when the participants were aware of the projection of the boiling motion. We believe that it is important to investigate the effect of the projections when the participants were aware of the projections to understand the effect when the projections were actually used in dining and restaurants. On the other hand, the fact that most participants were aware of the projection may have biased their answers. Meanwhile, from the perceived of curry after tasting, it was shown that the participants rated curry was hotter at $60^{\circ} \mathrm{C}$ than at $50^{\circ} \mathrm{C}$. Since they correctly rated the temperature of curry, their ratings were thought to be reliable.

From the results of this experiment, some of the taste expectations (smell, hotness, price, palatability and appetite) were increased when the participants saw the projected effect. Most of the taste expectations did not affect perceptions or value judgments after the tasting, but only appetite was found to be affected after the tasting. On the other hand, the perceived saltiness and spice level after tasting were affected by the projected effects, which were not influenced before tasting. The reason for this result can be attributed to the expectation effect.

In this study, the appearance of food was altered. This led to cause discrepancies between the expectations before tasting and the impressions after tasting the participants had. In such a situation, the participants' perceived sensation can be explained by the expectation effect (Anderson, 1973; PiquerasFiszman and Spence, 2015). Some sort of expectation effect occurs when there is a discrepancy between the expectation and the actual experience. When the discrepancy is small, assimilation is subject to occur, which is the effect to bring an experienced sensation to the expectation. This is called the assimilation effect. Meanwhile, the larger the differences are between the expectation and the actual experience, the more likely a contrast will occur when the difference is greater than a certain level. This is the effect to keep the experienced impression away from the expectation to expand the difference. This is called the contrast effect. Furthermore, when the difference is within a certain range, neither assimilation nor contrast can occur. The expectation effects including the assimilation and the contrast effects are widely reported in the literature regarding food products. It is shown that the perceived tastes are likely to be influenced by the expectations formed from the appearance of food (Shankar et al., 2010; Shermer and Levitan 2014) or labels (Wansink et al., 2005; Yeomans et al., 2008) before tasting. As some research report, both assimilation (Wansink et al., 2005; Shankar et al., 2010) and contrast (Cardello and Sawyer 1992; Yeomans et al., 2008; Shermer and Levitan 2014) are observed in dining experiences. In this study, adding motion information can increase the participants' expectations and some sort of expectation effect could occur; however, perceived taste could settle down near the actual experience, which could lead to little difference caused by the projected effects in the evaluation after tasting. This could be the reason why the participants had the same level of ratings for all the curry samples after tasting and evaluated temperature of curry correctly.

On the other hand, the appetite was determined to be high when the boiling effect was projected before and after tasting. Because the participants tasted only a scoop of curry in each trial, the physiological appetite could not be affected; hence, the increased appetite was maintained after the tasting. When evaluating the palatability before tasting, the boiling effect increase the estimation. As the interaction contrast and 
multiple comparisons suggested, the $50^{\circ} \mathrm{C}$ curry received the higher score than the $60^{\circ} \mathrm{C}$ when the boiling effect projected. This difference could be caused by the heating process. To keep the temperature of the curry uniform under each condition, the curry was heated at $80^{\circ} \mathrm{C}$ and $65^{\circ} \mathrm{C}$ for $1 \mathrm{~h}$. This could change the components of the curry and affect the appearance. When comparing the pixel values of the heated curry photos, the curry heated at $80^{\circ} \mathrm{C}$ had a hue $=9.38$, a saturation $=162.55$, and a brightness $=120.88$. Meanwhile, the curry heated at $65^{\circ} \mathrm{C}$ had a hue $=9.40$, a saturation $=158.69$, and a brightness $=122.47$. Some research revealed that the expectations for food changed according to the differences in the chroma and brightness (Wei et al., 2012; Lee et al., 2013). In addition, the combination of continuously changing the brightness caused by the boiling effect and the minute difference in the curry color could influence the expectations for palatability.

Although estimation of spice level was not affected by the projected image nor the temperature, ratings after tasting showed the influence of the projected images. The increase in the perceived spice level could be explained by the mechanism of the spiciness sensation. The curry was added red pepper as a spice. The pungent component of red pepper is capsaicin, which evokes spiciness by activating TRPV1, a spiciness receptor in the oral cavity (Caterina et al., 1997; Zheng, 2013). TRPV1 also works as a temperature receptor and is activated at temperatures above $43^{\circ} \mathrm{C}$. The activation energy of TRPV 1 lowers with the rise in temperature; it leads to the increase of the number of activated receptors (Zheng, 2013), which is the reason why the pungent taste is perceived more strongly when the temperature rises. This perception characteristic 'the higher temperature is, the spicier a food is' will be learned. From this prior experience and unconscious knowledge, it is considered that appearance of piping hot food can be the key of predicting higher spiciness. Although no significant difference was observed in the effect of the projected images on the prediction of spice level, a marginally significant effect was observed. It suggested that expected spice level from its appearance was higher under the boiling effect texture than under the single-color image projection. At $50^{\circ} \mathrm{C}$, there was not a large difference between expected and actual spice level of curry. It followed that assimilation effect brought experienced spicy sensation to the expectation in both projection conditions. In the case of curry at $60^{\circ} \mathrm{C}$ with the boiling effect projected, there was also not a large difference between expected and actual spiciness, and assimilation was evoked. On the other hand, in the case of single-color image projection condition at $60^{\circ} \mathrm{C}$, the contrast seemed to be generated because of the larger gap between expected and actual spiciness; it led to higher evaluation of spice level. This could be the reason why the interaction effect between the image and the temperature was observed.

Estimation of saltiness was also not affected by the projected image nor the temperature but affected from the projected images after tasting. Previous research show that an angular shape is associated with saltiness compared to a round shape (Spence and Ngo 2012; Velasco et al., 2015; Huisman et al., 2016). The boiling effect was not in an angular shape but caused stimulating sensation, so the boiling effect could cause similar effect as an angular shape and reinforce the perception of saltiness during eating.

The experimental results showed that a projecting boiling texture on food does not cause much influence when eating food; however, some effects were observed before tasting. Considering the impact on participants before meals, especially on their appetite for food, it could be used for advertising purposes. Therefore, we conducted an empirical user study to investigate the effect of dynamic boiling texture on consumers' behavior on site.

\section{EMPIRICAL USER STUDY}

The aim of this study was to investigate the influence of the dynamic textures projected onto the food to determine the consumers' behavior. In Japan, it is popular in a restaurant to place food displays in the store front to attract customers and to draw them to the menu. This study explores the impact on the customers' behavior when dynamic textures are projected onto such displays.

\section{Method}

The study was conducted at 'Miraikan Kitchen' in 'Miraikan The National Museum of Emerging Science and Innovation' in Tokyo, Japan. For this study, 'setsugen curry' was selected as the target dish, which was provided at the restaurant during a special exhibition held at Miraikan. The dish was sold for 1020 JPY (approximately 9.4 USD), which is a little bit more expensive than other items on the menu, which are typically in the range of 600 to 780 JPY (approximately 5.5 USD to 7.2 USD). In addition, 'setsugen' means snowfield in Japanese. As the name indicates, the curry is white in color with a little bit of yellow although the color of the curry is usually brown. Unlike our previous study, this dish featured deep-fried chicken and broccoli as toppings. To provide a natural appearance for this location, the projected texture had a little yellowish gray color $(\mathrm{R}=104, \mathrm{G}=94, \mathrm{~B}=$ 58). The texture was partially masked to avoid projecting the texture on the toppings. The food showcase was placed at the entrance of the restaurant during the daytime for this investigation (Figure 10). The restaurant is a food-court style, long and narrow structure. Visitors can see the food showcases only at the entrance of the restaurant. The order-counter is far from the entrance, so the visitors can not see the food showcases while standing in line at the counter. By doing so, the effect of the difference in exposure time with the showcase due to longer waiting times etc., is less likely to appear. A projector was placed invisibly inside the food showcase, allowing projection mapping onto the food inside the case. Similar to previous experiment, two kinds of images were projected: one expressed a boiling motion and the other showed a single color (projection conditions) (Figure 11).

This survey was conducted over 4 days. The number of visitors usually differed greatly between a weekday and a holiday, but not so much between weekdays/holidays. Therefore, the food products under each projection condition were displayed in the showcase in front of the restaurant on one randomly 


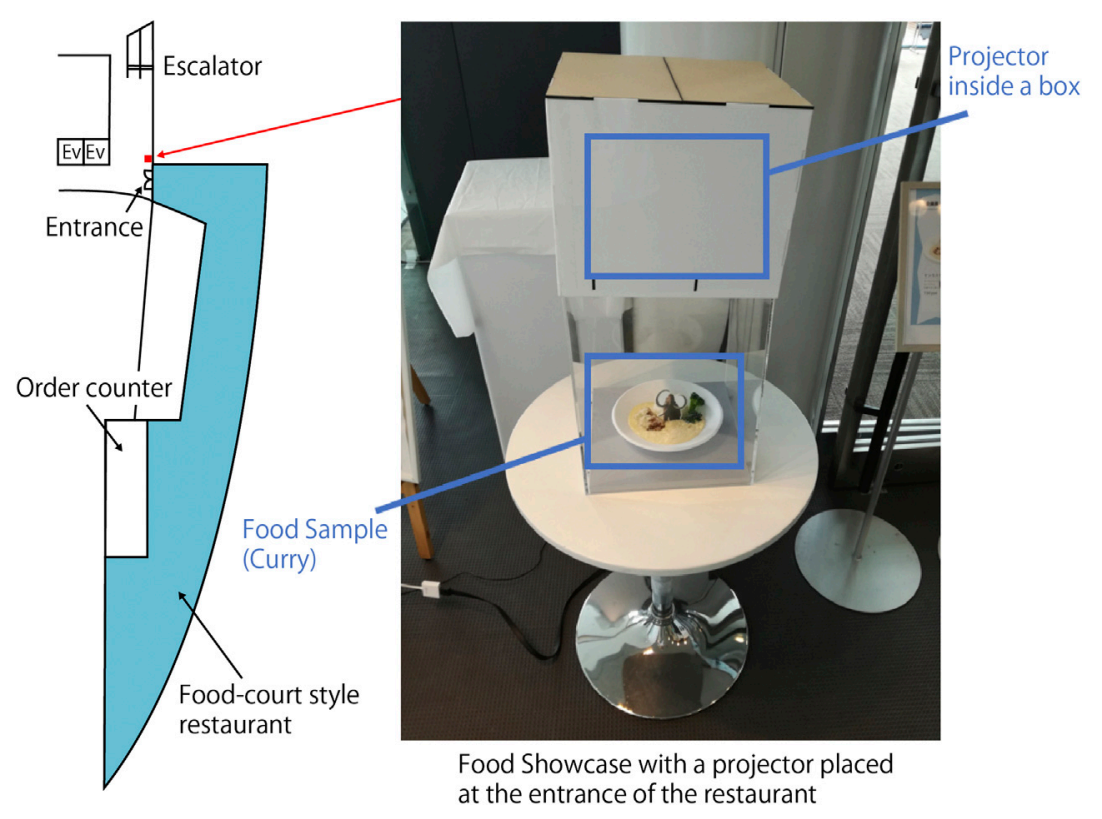

FIGURE 10 | Food showcase used in the study and where it was placed in the restaurant floor.

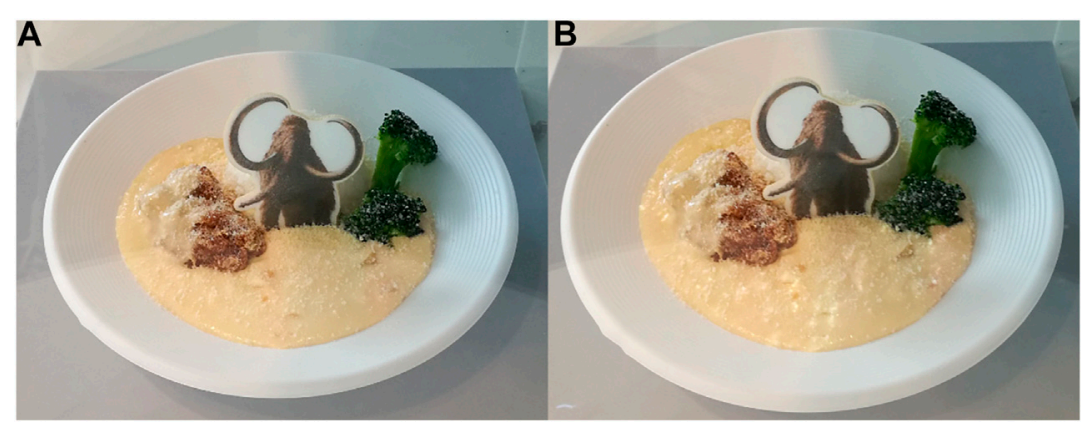

FIGURE 11 | (A) Curry with the single color projected and (B) with the boiling effect projected.

selected weekday and one randomly selected holiday. The number of customers at the restaurant and the number of orders of curry were counted, and the order rates (The number of orders/the number of customers) for the two conditions was compared.

\section{Results}

A total of 2353 people visited the restaurant during the study days and 216 plates of curry were ordered. For the days where a singlecolor texture was projected, 998 customers visited the restaurant, and 75 plates ( 0.075 plates per customer) were ordered. In contrast, for the days where the dynamic texture was projected, 1355 customers visited the restaurant, and 141 plates ( 0.104 plates per customer) were ordered. A test for the difference between the two rates showed that the order rate for the days in which the dynamic textures were projected was significantly higher than the other days $(z=2.400, p<0.05$, Cohen's Effect Size $h=0.102$ ) (Figure 12).

\section{Discussion}

The objective of this study was to explore how dynamic textures on food influences the consumers' behavior. The results from this study indicate that the projection-based boiling effect has potential to lead consumers to purchasing behavior. This effect can be explained by the increased appetite due to the projectionbased boiling effect. Some studies have reported that consumers buy more food when they feel hungry (Nisbett and Kanouse 1968; Gilbert et al., 2002). From the results of our laboratory experiment, it can be suggested that dynamic textures increase the appetite of consumers. As a result, the increased appetite is linked to hunger; thus, the dynamic textures may have been associated with consumers' willingness to buy. 


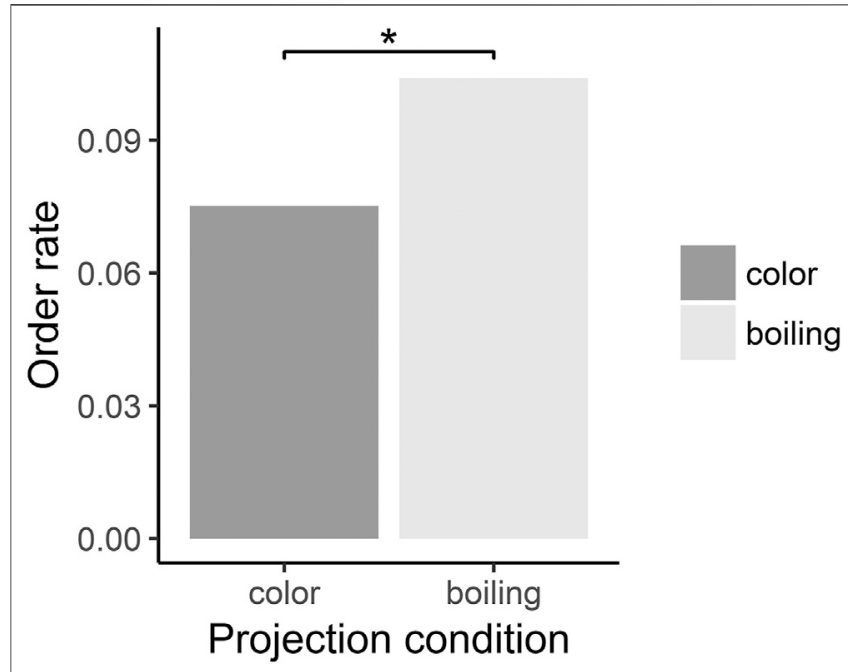

FIGURE 12 | Order rates of the curry. The "*” mark represents a significant difference where $p<0.05$.

Furthermore, the results of our laboratory experiment indicate that the dynamic texture increases willingness-to-pay by consumers. It will provide consumers with the expectation that the target food is worth to purchasing from the viewpoint of pricing. Although the target food product (setsugen curry) was more expensive than the other plates the restaurant provided, the order rate of for such a costly meal was increased. It indicates that the dynamic texture has potential for the consumers to pay more for the meal.

In this experiment, evaluation of the curry after tasting was not investigated. Even so, since evaluation after tasting was not lowered by the projected boiling effect in the previous experiment, it is expected that the consumers were not disappointed with a gap between expected and real taste.

However, since this experiment was conducted in a week, there is a possibility that the consumers who visit the restaurant may differ depending on the day of the week. In addition, this experiment was carried out in the science museum, and customers might be attracted by the unusual presentation of menu using a novel technique. The fact that the results may have been conditioned by biases associated with some participants being particularly interested in the new technology is a clear implication of this empirical user study. This point needs to be verified further. Although the number of days to conduct the experiment was limited due to the constraints of the site, it is important to investigate how the effect changes when the technology is used for a long period of time, in order to investigate the effect of removing the novelty of the new technology. Similarly, due to the constraints of the site, it was not possible to investigate what kind of decisions were made by the people who actually ordered food at the restaurant through interviews or other means. It would be useful to conduct such a survey in the future in order to link purchasing behavior with consumer perception and judgment. Moreover, comparisons with past/usual sales will allow for more precise verification. It was not possible this time due to the circumstances of the restaurant. Then we will do more rigorous verification in the wild as future work.

\section{GENERAL DISCUSSION}

\section{Conclusion}

This article explores the dynamic textures' influence on the dining experience and the consumers' behavior. In the laboratory experiment, projecting the boiling effect was suggested to cause an expected increase in terms of the smell, hotness, price, palatability, and the appetite for curry before tasting. Although the proposed method raised the expectations before tasting the curry, it also showed that some effects were not observed during the actual tasting.

Meanwhile, the influence of the boiling effect on perceived saltiness and spice level were observed only after tasting (the reasons were discussed in the discussion of the experiment). Currently, excessive intake of salt is a serious problem (Mente et al., 2014; O'Donnell et al., 2014). According to the guideline of $\mathrm{WHO}$, it is desirable to suppress salt intake less than $5 \mathrm{~g}$ per day (W. G. A. by the Guidelines Review Committee, 2012), but it is difficult to achieve the goal. Since dishes with the boiling motion texture are thought to be perceived saltier, this effect can help to reduce salt intake.

As described above, the boiling effect has a power to promote appetite and increase expected price. Moreover, as the result of the empirical user study suggested, these outcomes could prompt consumer to buy targeted food products. In Japan, there is a culture to display food samples in showcases at restaurants to attract customers. From this research, projecting dynamic textures could raise the consumers' expectations for the food; therefore, applying dynamic textures to food samples may attract more visitors. From this concept, in the empirical user study, dynamic textures were projected on a food display at a restaurant. Afterwards, the order rate of the targeted food was examined. The results indicate that the dynamic texture increases the order rate, which can be mediated by the increased appetite.

This study investigated the effect of the dynamic texture on the dining experience. This investigation revealed that the dynamic texture has potential to increase the expectation for the dishes and promote the consumers' purchasing intentions. Although the effect of static textures on food has been widely investigated, little knowledge has been provided about how dynamic textures affect the dining experience. By introducing this unique technique into the culinary industry, we believe that this study can introduce a new perspective into this research area. To stimulate the willingness of consumers to purchase items, marketers have applied various methods, such as changing labeling (Wansink et al., 2001; de Waal Malefyt, 2015), attractive catch copies (Elder and Krishna, 2009), and health claims (Peschel et al., 2019). This technique can provide a new approach to get consumers to purchase attractive food.

\section{Limitations and Future Research}

This study focused on the influence of the boiling effect projected on curry. As the influence of projecting other dynamic textures on other food items was not investigated in this study, it is necessary to consider whether the results of this research can be applied to other food products. We also have not tested the pure effect of dynamic texture 
projection by direct comparison with the condition without any projection or the blindfolded condition. In the current study, to investigate only the effect of dynamic texture by eliminating as much as possible the effect of changes in other visual features, we decided to use a static single-color image projection as the control condition. It would be interesting to compare with the blindfolded condition to verify the absolute impact of the total appearance realized by our projection mapping technique, including the dynamic texture, on food perception. Moreover, as stated in 3.3, the fact that most participants were aware of the projection may have biased their answers. Therefore, it is necessary to conduct a follow-up experiment to look into the bias by using a setup where the projection mapping is difficult to be aware of and by examining the difference in the effect when the type of the projected image is changed (ex. Food-related motion such as boiling vs. random motion).

In addition, this research also failed to clarify which component of the dynamic texture has an influence on the taste of food. In static images, Arce-Lopera et al. (2015) demonstrated the changes in the asymmetry of the luminance distribution, which is related to the freshness of the vegetables. Similarly, a relationship could be established between the dynamic texture of food and their characteristics, such as the speed of motion, temperature, or viscosity. For future studies, further examinations on the dynamic textures, such as the frequency, pattern, and contrast, and how it compares to expectations of taste, needs to be further explored. By applying a dynamic texture to food, this will make the meals more attractive to consumers.

\section{DATA AVAILABILITY STATEMENT}

The raw data supporting the conclusions of this article will be made available by the authors, without undue reservation.

\section{REFERENCES}

Alfnes, F., Guttormsen, A. G., Steine, G., and Kolstad, K. (2006). Consumers' Willingness to Pay for the Color of Salmon: A Choice Experiment with Real Economic Incentives. Am. J. Agric. Econ. 88 (4), 1050-1061. doi:10.1111/j.1467-8276.2006.00915.x

Anderson, R. E. (1973). Consumer Dissatisfaction: The Effect of Disconfirmed Expectancy on Perceived Product Performance. J. Marketing Res. 10 (1), 38-44. doi:10.1177/002224377301000106

Arce-Lopera, C., Masuda, T., Kimura, A., Wada, Y., and Okajima, K. (2015). Model of Vegetable Freshness Perception Using Luminance Cues. Food Qual. Preference 40, 279-286. doi:10.1016/j.foodqual.2014.06.010

Aslam, M. M. (2006). Are You Selling the Right Colour? a Cross-Cultural Review of Colour as a Marketing Cue. J. marketing Commun. 12 (1), 15-30. doi:10.1080/ 13527260500247827

Cardello, A. V., and Sawyer, F. M. (1992). Effects of Disconfirmed Consumer Expectations on Food Acceptability. J. Sensory Stud. 7 (4), 253-277. doi:10. 1111/j.1745-459x.1992.tb00194.x

Cardello, A. V., and Schutz, H. G. (2003). The Concept of Food Freshness: Uncovering its Meaning and Importance to Consumers. Freshness Shelf Life of Foods 836, 22-41.

Caterina, M. J., Schumacher, M. A., Tominaga, M., Rosen, T. A., Levine, J. D., and Julius, D. (1997). The Capsaicin Receptor: a Heat-Activated Ion Channel in the Pain Pathway. Nature 389 (6653), 816-824. doi:10.1038/39807

Chang, H. H., and Tuan Pham, M. (2013). Affect as a Decision-Making System of the Present. J. Consumer Res. 40 (1), 42-63. doi:10.1086/668644

\section{ETHICS STATEMENT}

The studies involving human participants were reviewed and approved by The ethics committee in the Graduate School of Information Science and Technology, The University of Tokyo. The patients/participants provided their written informed consent to participate in this study.

\section{AUTHOR CONTRIBUTIONS}

Conceived and designed the experiments: YS, TN, TT, and MH. Performed the experiments: YS. Analyzed the data: YS and TN. Wrote the paper: YS, TN, TT, and MH.

\section{FUNDING}

This work was supported by JSPS Grant-in-Aid for Scientific Research on Innovative Areas (grant number JP18H05002).

\section{ACKNOWLEDGMENTS}

The empirical study was conducted as a part of the special program "Miraikan’s openlabo" in Miraikan.

\section{SUPPLEMENTARY MATERIAL}

The Supplementary Material for this article can be found online at: https://www.frontiersin.org/articles/10.3389/fcomp.2021.662824/ full\#supplementary-material

Chung, L. M. Y., and Fong, S. S. M. (2018). Appearance Alteration of Fruits and Vegetables to Increase Their Appeal to and Consumption by School-Age Children: A Pilot Study. Health Psychol. open 5 (2), 2055102918802679. doi:10.1177/2055102918802679

Clement, J. (2007). Visual Influence on In-Store Buying Decisions: An Eye-Track Experiment on the Visual Influence of Packaging Design. J. marketing Manag. 23 (9-10), 917-928. doi:10.1362/026725707×250395

de Waal Malefyt, T. (2015). Relationship Advertising: How Advertising Can Enhance Social Bonds. J. Business Res. 68 (12), 2494-2502. doi:10.1016/j. jbusres.2015.06.036

Doretto, G., Chiuso, A., Wu, Y. N., and Soatto, S. (2003). Dynamic Textures. Int. J. Comp. Vis. 51, 91-109. doi:10.1023/a:1021669406132

Elder, R. S., and Krishna, A. (2009). The Effects of Advertising Copy on Sensory Thoughts and Perceived Taste. J. consumer Res. 36 (5), 748-756.

Fujimoto, Y. (2018). Projection Mapping for Enhancing the Perceived Deliciousness of Food. IEEE Access 6, 59975-59985. doi:10.1109/access.2018. 2875775

Gilbert, D. T., Gill, M. J., and Wilson, T. D. (2002). The Future Is Now: Temporal Correction in Affective Forecasting. Organizational Behav. Hum. Decis. Process. 88 (1), 430-444. doi:10.1006/obhd.2001.2982

Gvili, Y., Tal, A., Amar, M., Hallak, Y., Wansink, B., Giblin, M., et al. (2015). Fresh from the Tree: Implied Motion Improves Food Evaluation. Food Qual. Preference 46, 160-165. doi:10.1016/j.foodqual.2015.07.015

Hagtvedt, H., and Patrick, V. M. (2008). Art Infusion: The Influence of Visual Art on the Perception and Evaluation of Consumer Products. J. Marketing Res. 45 (3), 379-389. doi:10.1509/jmkr.45.3.379 
Harrar, V., and Spence, C. (2013). The Taste of Cutlery: How the Taste of Food Is Affected by the Weight, Size, Shape, and Colour of the Cutlery Used to Eat it. Flavour 2 (1), 21

Huisman, G., Bruijnes, M., and Heylen, D. K. (2016). "A Moving Feast: Effects of Color, Shape and Animation on Taste Associations and Taste Perceptions," in Proceedings of the 13th International Conference on Advances in Computer Entertainment Technology, Osaka, Japan, November 9-12, 2016, 13.

Kawabe, T., Fukiage, T., Sawayama, M., and Nishida, S. (2016). Deformation Lamps: A Projection Technique to Make Static Objects Perceptually Dynamic. ACM Trans. Appl. Perception (TAP) 13 (2), 10. doi:10.1145/2874358

Kruger, J., Wirtz, D., Van Boven, L., and Altermatt, T. W. (2004). The Effort Heuristic. J. Exp. Soc. Psychol. 40 (1), 91-98. doi:10.1016/s0022-1031(03) 00065-9

Kuvykaite, R., Dovaliene, A., and Navickiene, L. (2009). Impact of Package Elements on Consumer's Purchase Decision. Econ. Manag. (14), 441-447.

Labrecque, L. I., and Milne, G. R. (2012). Exciting Red and Competent Blue: The Importance of Color in Marketing. J. Acad. Mark. Sci. 40 (5), 711-727. doi:10. 1007/s11747-010-0245-y

Lee, S.-M., Lee, K.-T., Lee, S.-H., and Song, J.-K. (2013). Origin of Human Colour Preference for Food. J. Food Eng. 119 (3), 508-515. doi:10.1016/j.jfoodeng.2013. 06.021

Loebnitz, N., and Grunert, K. G. (2015). The Effect of Food Shape Abnormality on Purchase Intentions in china. Food Qual. Preference 40, 24-30. doi:10.1016/j. foodqual.2014.08.005

Mente, A., O'Donnell, M. J., Rangarajan, S., McQueen, M. J., Poirier, P., Wielgosz, A., et al. (2014). Association of Urinary Sodium and Potassium Excretion with Blood Pressure. N. Engl. J. Med. 371 (7), 601-611. doi:10. 1056/nejmoa1311989

Michel, C., Velasco, C., Fraemohs, P., and Spence, C. (2015). Studying the Impact of Plating on Ratings of the Food Served in a Naturalistic Dining context is Acknowledgements: CM Is the Chef-In-Residence at the Crossmodal Research Laboratory, University of Oxford. CV Would like to Thank COLFUTURO for Part Funding His PhD. CS Would like to Thank the AHRC Who Funded the 'Rethinking the Senses' Project (AH/L007053/1). 弥. Appetite 90, 45-50. doi:10.1016/j.appet.2015.02.030

Michel, C., Velasco, C., Gatti, E., and Spence, C. (2014). A Taste of Kandinsky: Assessing the Influence of the Artistic Visual Presentation of Food on the Dining Experience. Flavour 3 (1), 7. doi:10.1186/2044-7248-3-7

Nishizawa, M., Jiang, W., and Okajima, K. (2016). "Projective-AR System for Customizing the Appearance and Taste of Food," in Proceedings of the 2016 workshop on Multimodal Virtual and Augmented Reality, 6.

Morrot, G., Brochet, F., and Dubourdieu, D. (2001). The Color of Odors. Brain Lang. 79 (2), 309-320. doi:10.1006/brln.2001.2493

Nakano, K., Kiyokawa, K., Horita, D., Yanai, K., Sakata, N., and Narurni, T. (2019). "Enchanting Your Noodles: A Gustatory Manipulation Interface by Using GAN-based Real-Time Food-To-Food Translation," in IEEE Conference on Virtual Reality and 3D User Interfaces (VR), Osaka, Japan, March 23-27, 2019 (IEEE), 1339-1340.

Narumi, T., Ban, Y., Kajinami, T., Tanikawa, T., and Hirose, M. (2012). "Augmented Perception of Satiety: Controlling Food Consumption by Changing Apparent Size of Food with Augmented Reality," in Proceedings of the SIGCHI Conference on Human Factors in Computing Systems, Austin, TX, May 5-10, 2012 (ACM), 109-118.

Narumi, T., Nishizaka, S., Kajinami, T., Tanikawa, T., and Hirose, M. (2011). "Augmented Reality Flavors: Gustatory Display Based on Edible Marker and Cross-Modal Interaction," in Proceedings of the SIGCHI Conference on Human Factors in Computing Systems, Vancouver, BC, May 7-12, 2011 (ACM), 93-102.

Nisbett, R. E., and Kanouse, D. E. (1968). "Obesity, Hunger, and Supermarket Shopping Behavior," in Proceedings of the Annual Convention of the American Psychological Association, San Francisco, CA, August 30-September 3, 1968 (American Psychological Association). doi:10.1037/e473742008-343

O’Donnell, M., Mente, A., Rangarajan, S., McQueen, M. J., Wang, X., Liu, L., et al. (2014). Urinary Sodium and Potassium Excretion, Mortality, and Cardiovascular Events. N. Engl. J. Med. 371 (7), 612-623. doi:10.1056/nejmoal311889

Paakki, M., Sandell, M., and Hopia, A. (2019). Visual Attractiveness Depends on Colorfulness and Color Contrasts in Mixed Salads. Food Qual. Preference 76, 81-90. doi:10.1016/j.foodqual.2019.04.004
Peschel, A. O., Orquin, J. L., and Mueller Loose, S. (2019). Increasing Consumers' Attention Capture and Food Choice through Bottom-Up Effects. Appetite 132, 1-7. doi:10.1016/j.appet.2018.09.015

Pham, M. T., and Avnet, T. (2009). Contingent Reliance on the Affect Heuristic as a Function of Regulatory Focus. Organizational Behav. Hum. Decis. Process. 108 (2), 267-278. doi:10.1016/j.obhdp.2008.10.001

Piqueras-Fiszman, B., and Spence, C. (2015). Sensory Expectations Based on Product-Extrinsic Food Cues: An Interdisciplinary Review of the Empirical Evidence and Theoretical Accounts. Food Qual. Preference 40, 165-179. doi:10. 1016/j.foodqual.2014.09.013

Sakurai, S., Narumi, T., Ban, Y., Tanikawa, T., and Hirose, M. (2013). "Affecting Our Perception of Satiety by Changing the Size of Virtual Dishes Displayed with a Tabletop Display," inInternational Conference on Virtual, Augmented and Mixed Reality, Las Vegas, NV, July 21-26, 2013 (Springer), 90-99. doi:10.1007/978-3-642-39420-1_11

Schütte, S. (2013). Evaluation of the Affective Coherence of the Exterior and Interior of Chocolate Snacks. Food Qual. Preference 29 (1), 16-24. doi:10.1016/j. foodqual.2013.01.008

Shankar, M., Simons, C., Shiv, B., McClure, S., Levitan, C. A., and Spence, C. (2010). An Expectations-Based Approach to Explaining the Cross-Modal Influence of Color on Orthonasal Olfactory Identification: The Influence of the Degree of Discrepancy. Atten. Percep.Psychophys. 72 (7), 1981-1993. doi:10. 3758/app.72.7.1981

Shermer, D. Z., and Levitan, C. A. (2014). Red Hot: The Crossmodal Effect of Color Intensity on Perceived Piquancy. Multisensory Res. 27 (3-4), 207-223. doi:10. 1163/22134808-00002457

Spence, C., and Ngo, M. K. (2012). Assessing the Shape Symbolism of the Taste, Avour, and Texture of Foods and Beverages. Flavour 1 (1), 12. doi:10.1186/ 2044-7248-1-12

Spence, C. (2018). Why Are Animate Dishes So Disturbing?. Int. J. Gastronomy Food Sci. 13, 73-77. doi:10.1016/j.ijgfs.2018.07.001

Steenkamp, J.-B. E. M., and van Trijp, H. C. M. (1996). Quality Guidance: A Consumer-Based Approach to Food Quality Improvement Using Partial Least Squares. Eur. Rev. Agric. Econ. 23 (2), 195-215. doi:10.1093/erae/ 23.2.195

van Rompay, T. J. L., De Vries, P. W., Bontekoe, F., and Tanja-Dijkstra, K. (2012). Embodied Product Perception: Effects of Verticality Cues in Advertising and Packaging Design on Consumer Impressions and Price Expectations. Psychol. Mark. 29 (12), 919-928. doi:10.1002/mar.20574

Velasco, C., Woods, A. T., Deroy, O., and Spence, C. (2015). Hedonic Mediation of the Crossmodal Correspondence between Taste and Shape. Food Qual. Preference 41, 151-158. doi:10.1016/j.foodqual.2014.11.010

Wada, Y., Arce-Lopera, C., Masuda, T., Kimura, A., Dan, I., Goto, S.-i., et al. (2010). Influence of Luminance Distribution on the Appetizingly Fresh Appearance of Cabbage. Appetite 54 (2), 363-368. doi:10.1016/j.appet.2010.01.002

Wansink, B., Painter, J., and Ittersum, K. V. (2001). Descriptive Menu Labels' Effect on Sales. Cornell Hotel Restaurant Adm. Q. 42 (6), 68-72. doi:10.1177/ 0010880401426008

Wansink, B., van Ittersum, K., and Painter, J. E. (2005). How Descriptive Food Names Bias Sensory Perceptions in Restaurants. Food Qual. preference 16 (5), 393-400. doi:10.1016/j.foodqual.2004.06.005

Wei, S.-T., Ou, L.-C., Luo, M. R., and Hutchings, J. B. (2012). "The Relationship between Visual Perceptions and Taste Expectations Using Food Colours," in Predicting Perceptions: The 3rd International Conference on Appearance, Edinburgh, Scotland, April 17-19, 2012 (Edinburgh, UK).

Guidelines Review Committee (2012). Guideline: Sodium Intake for Adults and Children. Geneva: World Health Organization.

Yeomans, M. R., Chambers, L., Blumenthal, H., and Blake, A. (2008). The Role of Expectancy in Sensory and Hedonic Evaluation: The Case of Smoked Salmon Ice-Cream. Food Qual. preference 19 (6), 565-573. doi:10.1016/j.foodqual.2008. 02.009

Zampini, M., Sanabria, D., Phillips, N., and Spence, C. (2007). The Multisensory Perception of Flavor: Assessing the Influence of Color Cues on Flavor Discrimination Responses. Food Qual. Preference 18 (7), 975-984. doi:10. 1016/j.foodqual.2007.04.001

Zellner, D. A., Lankford, M., Ambrose, L., and Locher, P. (2010). Art on the Plate: Effect of Balance and Color on Attractiveness of, Willingness to Try and Liking 
for Food. Food Qual. Preference 21 (5), 575-578. doi:10.1016/j.foodqual.2010. 02.007

Zellner, D. A., Loss, C. R., Zearfoss, J., and Remolina, S. (2014). It Tastes as Good as it Looks! The Effect of Food Presentation on Liking for the Flavor of Food 2 ' Appetite 77, 31-35. doi:10.1016/j.appet.2014.02.009

Zellner, D. A., Siemers, E., Teran, V., Conroy, R., Lankford, M., Agrafiotis, A., et al. (2011). Neatness Counts. How Plating Affects Liking for the Taste of Food. Appetite 57 (3), 642-648. doi:10.1016/j.appet.2011.08.004

Zheng, J. (2013). Molecular Mechanism of TRP Channels. Compr. Physiol. 3 (1), 221-242. doi:10.1002/cphy.c120001
Conflict of Interest: The authors declare that the research was conducted in the absence of any commercial or financial relationships that could be construed as a potential conflict of interest.

Copyright (อ 2021 Suzuki, Narumi, Tanikawa and Hirose. This is an open-access article distributed under the terms of the Creative Commons Attribution License (CC $B Y)$. The use, distribution or reproduction in other forums is permitted, provided the original author(s) and the copyright owner(s) are credited and that the original publication in this journal is cited, in accordance with accepted academic practice. No use, distribution or reproduction is permitted which does not comply with these terms. 